\title{
Periodontal Disease, CTCAE
}

National Cancer Institute

\section{Source}

National Cancer Institute. Periodontal Disease, CT CAE. NCI Thesaurus. Code C57849.

A disorder in the gingival tissue around the teeth. 